\title{
Simulating the Adsorption Isotherms of Methane, Ethane, and Propane in the Zeolite Silicalite
}

\author{
Berend Smit \\ Shell Research B.V., Koninklijke/Shell-Laboratorium, Amsterdam, P.O. Box 38000, \\ 1030 BN Amsterdam, The Netherlands
}

Received: November 16, 1994; In Final Form: January 9, $1995^{\circledR}$

\begin{abstract}
Computer simulations are used to simulate the adsorption isotherms of methane, ethane, and propane in the zeolite silicalite. Various zeolite-alkane models have been tested via a comparison with experimental heats of adsorption and Henry coefficients. These tests are used to improve the existing models. It is shown that the calculated adsorption isotherms agree well with the available experimental data. However, a definitive validation of the models is impeded by the large scatter of reported experimental data.
\end{abstract}

\section{Introduction}

Zeolites are complex, crystalline inorganic materials which have a well defined microporous structure. Their high internal surface, internal acidity, and thermal stability are some of the unique properties that make them an important class of catalytic materials for petrochemical processes. ${ }^{1}$

In many practical applications of zeolites it is important to know the amount of material adsorbed inside their pores. Experimentally, it is difficult to obtain this type of information, in particular at reaction conditions. Computer simulations appear to be an attractive alternative to experimentation for determining the adsorption isotherms at conditions of interest. One of the first attempts to study the thermodynamic properties of a molecule adsorbed in a zeolite was made by Stroud et al. ${ }^{2}$ Since this pioneer work, many articles have been published describing the use of molecular dynamics or Monte Carlo techniques to study the behavior of molecules adsorbed in zeolites. $^{3-38}$ A review of some of these simulation studies is given in ref 39 .

In this paper we study the adsorption isotherms of methane, ethane, and propane in the zeolite silicalite. The technical details of the simulation techniques used are described in ref 40 . A discussion of the models that are used in this work is given in section II, details of the simulations are described in section III, and the results are listed in sections IV-VI.

\section{Models}

In this paper we focus on the adsorption of small alkanes in silicalite. Following Kiselev and co-workers, ${ }^{41}$ we have assumed that the zeolite crystal is rigid. The silicalite structure is of the orthorhombic form with atomic positions taken from the X-ray diffraction. ${ }^{42}$ In some studies the importance of a flexible zeolite structure is emphasized. ${ }^{16,25}$ We expect that this framework flexibility can be of importance for the modeling of the diffusion of the molecules, since a flexible framework may reduce the diffusion barriers. Since these barriers correspond to positions in which the molecules have a relatively high energy and therefore do not contribute much to the equilibrium properties, it can be expected that the assumption of a rigid zeolite lattice is less severe for these properties. Important to note is that the adsorption of molecules may induce structural transitions of the zeolite lattice. ${ }^{43}$ Since the techniques used in this work can also be used with a flexible framework-this will,

${ }^{\otimes}$ Abstract published in Advance ACS Abstracts, March 15, 1995. however, require significantly more CPU-time-it would be interesting to test the validity of the assumption of a rigid framework.

For the adsorption of alkanes it is reasonable to assume that the alkane-zeolite interactions are dominated by dispersive forces, which are described with a Lennard-Jones potential

$$
U\left(r_{i j}\right)= \begin{cases}4 \epsilon_{i j}\left[\left(\frac{\sigma_{i j}}{r_{i j}}\right)^{12}-\left(\frac{\sigma_{i j}}{r_{i j}}\right)^{6}\right] & r_{i j} \leq R_{\mathrm{c}} \\ 0 & r_{i j}>R_{\mathrm{c}}\end{cases}
$$

where $r_{i j}$ is the distance between atoms $i$ and $j, \epsilon$ is the energy parameter, $\sigma$ is the size parameter, and $R_{\mathrm{c}}$ is the cutoff radius of the potential. The contribution of the atoms beyond the cutoff to the total energy is estimated using the usual tail corrections. ${ }^{44}$ Since the size as well as the polarizability of the $\mathrm{Si}$ atoms are much smaller than those of the $\mathrm{O}$ atoms of the zeolite, it is assumed that the contributions of these $\mathrm{Si}$ atoms can be accounted for by using effective interactions with the $\mathrm{O}$ atoms.

The alkane molecules are modeled as united atoms; i.e., $\mathrm{CH}_{4}$, $\mathrm{CH}_{3}$, and $\mathrm{CH}_{2}$ are considered a single interaction center. The interactions between these united atoms are also described with Lennard-Jones potentials. More details on the parameters for the various interactions are given in sections IV-VI.

Since in our model the zeolite is assumed to be a rigid crystal, the potential energy at a given point inside the zeolite can be calculated a priori. If this is done for points on a grid, the potential energy at an arbitrary point can be estimated from interpolation during the simulations. ${ }^{37}$ With such an interpolation scheme a gain in CPU time of $1-2$ orders of magnitude can be gained.

\section{Simulation Details}

Most of the simulation studies investigate the energetics, siting, or diffusion of the adsorbed molecules, and only a few results on the simulation of isotherms have been reported. Soto and Myers ${ }^{3}$ used grand canonical Monte Carlo simulations to determine the adsorption isotherm of krypton in the molecular sieve MS-13X. A similar technique was used by Wood and Rowlinson ${ }^{45}$ to determine the adsorption isotherms of xenon and methane in zeolite $\mathrm{X}$ and $\mathrm{Y}$, by Goodbody et al $^{15}$ and by Theodorou and co-workers ${ }^{13,28}$ for methane in silicalite, by Van Tassel et al..$^{32.35}$ for xenon, argon, and methane in zeolite $\mathrm{NaA}$, and by Jameson et al. ${ }^{34}$ for xenon in zeolite $\mathrm{Na}-\mathrm{A}$. Adsorption isotherms of mixtures were calculated by Karavias and Myers ${ }^{18}$ for a mixtures of ethene-carbon dioxide as well as carbon 
dioxide-methane in zeolite X, by Maddox and Rowlinson ${ }^{30}$ for a mixture of nitrogen and methane in zeolite $\mathrm{Y}$, and by van Tassel et al. ${ }^{35}$ for mixtures of noble gases and methane in the zeolite $\mathrm{Na}-\mathrm{A}$.

In this work we have used ordinary $N, V, T$ simulations of one molecule adsorbed in silicalite to determine the Henry coefficients and heats of adsorption at zero loading. For ethane and propane we have used the configurational-bias Monte Carlo technique to determine the Henry coefficients; details on this technique in the context of simulations in zeolites can be found in ref 37. For the simulations of the adsorption isotherms we have used the grand canonical Monte Carlo method which is described in detail. More details on this technique can be found in ref 40. Below we give some of the details of the simulations that are specific for the various systems that have been studied. All simulations have been performed at a temperature of 298 $\mathrm{K}$.

A. Methane. The $N, V, T$ simulations were performed in cycles; each cycle consists of an attempt to displace a particle or an attempt to place the molecule at a new, randomly selected position. The probability to perform these two moves was set a priori such that on average $80 \%$ of the moves were attempts to displace a particle and $20 \%$ were attempts to move to a new position. In the displacement move the maximum displacement was given such a value that $50 \%$ of the moves were accepted. During the attempts to place the molecule at a random position, the "test-particle" energy was calculated from which the Henry coefficient was determined (see ref 47). A total simulation consisted of at least $10^{6}$ cycles.

Also the grand canonical simulations were performed in cycles, each cycle consisting of an attempt to displace a particle and an attempt to add or remove a particle. The relative probability of these Monte Carlo moves was such that $90 \%$ of the moves were attempts to displace a particle and $10 \%$ of the moves were attempts to add or remove a particle. At higher loadings the number of attempts to add or remove a particle was increased to $30 \%$. The simulations were started from the end configuration of a simulation at a lower chemical potential. We have allowed for at least $10^{4}$ equilibrium cycles, and the subsequent production runs for at least $10^{4}$ cycles at low loading and $10^{5}$ cycles at high loadings. Tests for several loadings showed that this number of equilibrium cycles was sufficient to obtain equilibrium.

B. Ethane. In addition to the moves used for methane, in the $N, V, T$ simulations of ethane an attempt was made to change the orientation of the ethane molecule by performing a rotation of the molecule. The maximum rotation was set to such a value that $50 \%$ of the moves were accepted. The relative probabilities of the attempts were such that $15 \%$ of the attempts were displacements, $15 \%$ rotations, and $60 \%$ of the moves attempts were to regrow the ethane molecule at a random position. For the latter move we have used the configurational-bias Monte Carlo scheme. In this scheme a molecule is grown atom by atom, and for each growing step we used three trial orientations. ${ }^{37,47}$ A total simulation consisted of at least $10^{6}$ cycles.

For the grand canonical Monte Carlo simulations the relative probabilities were $30 \%$ attempts to displace a particle, $30 \%$ attempts to change its orientation, and $50 \%$ attempts to add or remove a particle. Although for ethane it is possible to add or remove a particle using the conventional grand canonical Monte Carlo technique, we found it more efficient (a factor of 1.5-2) to use the combination of grand canonical Monte Carlo and the configurational-bias Monte Carlo technique as described in part I. In this scheme we used three trial orientations. A total
TABLE 1: Experimental Heat of Adsorption $\left(q_{\mathrm{st}}\right)$ of Methane, Ethane, and Propane in Silicalite/ZSM-5 ${ }^{a}$

\begin{tabular}{|c|c|c|c|c|}
\hline$T(\mathrm{~K})$ & $\mathrm{Si} / \mathrm{Al}$ ratio & $-q_{\mathrm{st}}(\mathrm{kJ} / \mathrm{mol})$ & method & ref \\
\hline \multicolumn{5}{|c|}{ Methane } \\
\hline 300 & $\infty$ & 18.1 & a & 20,63 \\
\hline 300 & $\infty$ (Linde S-115) & 20.4 & $\mathrm{a}$ & 51 \\
\hline 300 & $\infty$ & 20.5 & $\mathrm{~g}$ & 54 \\
\hline 300 & $\infty$ & 20.0 & $\mathrm{a}$ & 52 \\
\hline 300 & $\infty$ & 20.92 & $\mathrm{a}$ & 50,64 \\
\hline 300 & 52 & 28 & a & 48 \\
\hline 423 & $\infty$ & 22.5 & $\mathrm{~g}$ & 65 \\
\hline \multicolumn{5}{|c|}{ Ethane } \\
\hline 293 & 34 & 40.0 & a & 66 \\
\hline 293 & 130 & 45 & $\mathrm{a}$ & 66 \\
\hline 298 & $\infty$ & 30.5 & a & 60 \\
\hline 300 & $\infty$ (Linde S-115) & 32.8 & a & 51 \\
\hline 300 & $\infty$ & 29.9 & $\mathrm{~g}$ & 54 \\
\hline 300 & $\infty$ & 31 & a & 67 \\
\hline 301 & $\infty$ & 34 & $\mathrm{c}$ & 68 \\
\hline 318 & 1230 & 30 & $\mathrm{a}$ & 69 \\
\hline 333 & 132 & 30 & a & 59 \\
\hline \multicolumn{5}{|c|}{ Propane } \\
\hline 300 & $\infty$ & 42.2 & $?$ & 70 \\
\hline 293 & 34 & 44.5 & a & 66 \\
\hline 293 & 130 & 46.5 & $\mathrm{a}$ & 66 \\
\hline 298 & $\infty$ & 38 & a & 60 \\
\hline 300 & $\infty$ & 40.7 & $\mathrm{~g}$ & 54 \\
\hline 325 & $\infty$ (Linde S-115) & 39.9 & a & 51 \\
\hline 318 & 1230 & 40 & a & 69 \\
\hline 318 & 135 (Na,H-ZSM5) & 36.7 & $\mathrm{a}$ & 69 \\
\hline 333 & 132 & 39 & $\mathrm{a}$ & 59 \\
\hline 423 & $\infty$ & 36.5 & $\mathrm{~g}$ & 65 \\
\hline
\end{tabular}

${ }^{a}$ The experimental methods are (a) adsorption isotherms, (c) calorimetry, and (g) gas chromatography.

simulation consisted of $10^{4}$ equilibrium cycles and at least $10^{4}$ production cycles.

C. Propane. For the simulations of propane we used in addition to the moves described for ethane also a move in which part of the propane molecule is regrown; for this move the configurational-bias Monte Carlo scheme was used. ${ }^{46}$ This move ensures that the different bond angles of propane are sampled efficiently (neither displacements nor rotations affect the bond angle of this molecule). The probabilities of the various moves in the $N, V, T$ simulations were such that of the total number of moves $10 \%$ were attempts to displace, $10 \%$ attempts to rotate, $20 \%$ attempts to partly regrow the molecule, and $60 \%$ attempts to regrow the entire molecule at a random position. For the latter two moves we used four trial orientations. A total simulation consisted of at least $10^{6}$ cycles.

For the grand canonical Monte Carlo simulations the relative probabilities were such that $25 \%$ of the attempts were a displacement of a particle, $25 \%$ a rotation, $10 \%$ partly regrowing the molecule, and $40 \%$ adding or removing a particle. For the latter two moves we used four trial orientations. A total simulation consisted of $10^{5}$ equilibrium cycles and at least $10^{5}$ production cycles.

\section{Methane}

A. Experiments. Experimentally, the heat of adsorption of methane in silicalite/ZSM-5 has been determined using various methods. The results of these experiments are summarized in Table 1. The results reported by Papp et al. ${ }^{48}$ deviate significantly from the other data. The reason for this deviation may be the low $\mathrm{Si} / \mathrm{Al}$ ratio. Most other studies seem to agree on a value of about $-20 \mathrm{~kJ} / \mathrm{mol}$.

Adsorption isotherms of methane in silicalite have been determined by several groups. ${ }^{48-55}$ The results of these 


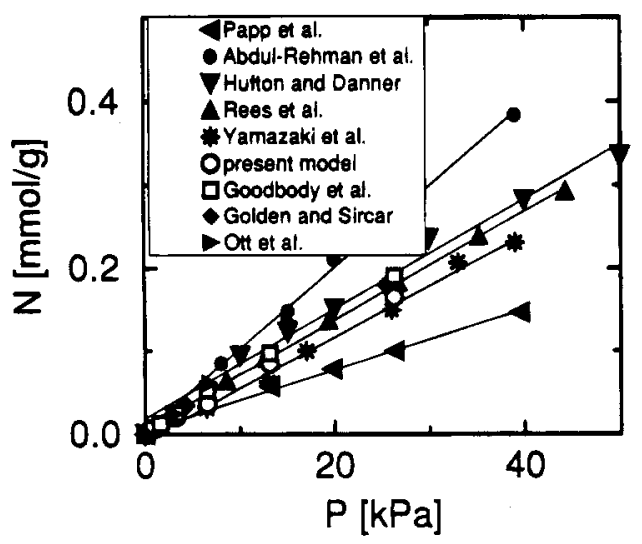

Figure 1. Experimental adsorption isotherms of methane in silicalite at low pressures (filled symbols). The lines show the fits from which the Henry coefficients have been determined, and the open symbols are the results from simulations at $T=298 \mathrm{~K}$.

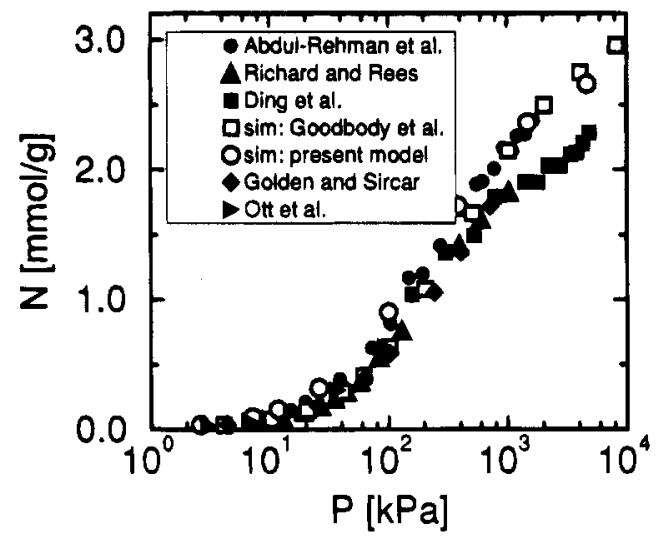

Figure 2. Adsorption isotherms of methane in silicalite. The open symbols are the results of simulations at $T=298 \mathrm{~K}$. The closed symbols are experimental data.

experimental studies are compared in Figure 1 at low pressures and in Figure 2 at high pressures. The agreement between these studies is not as good as one would like. At low pressures the data from Hufton and Danner, ${ }^{54}$ Yamazaki et al. ${ }^{50}$ Ott et al.,${ }^{53}$ Rees et al.,52 and Golden and Sircar ${ }^{55}$ are in very good agreement. The data from Abdul-Rehman et al. ${ }^{51}$ and Papp et al. ${ }^{48}$ appear to deviate significantly from the other results. A similar deviation of the result of Papp et al. for the heat of adsorption has been found. Abdul-Rehman et al. used Linde$\mathrm{S} 115$, and in order to compare the data with silicalite, we have assumed that the $10 \%$ binder (silica) contained in this material does not contribute to the adsorption. This assumption seems not to hold.

From the available adsorption isotherms we have determined the Henry coefficients; we use $K_{\mathrm{H}}=10.5 \mathrm{mg} /(\mathrm{g}$ atm $)$ as the experimental value for the Henry coefficient. ${ }^{56}$ Also at high pressures (see Figure 2) the results form Abdul-Rehman et al. deviate from the results of Rees et al. ${ }^{52}$ and Ding et al. ${ }^{49}$ The latter two, however, agree very well. Ding et al. ${ }^{49}$ however, did not use silicalite, but Na-ZSM-5 and the presence of $\mathrm{Na}$ could affect the accessible volume for the adsorbed molecules significantly. The theoretical maximum loading of methane is estimated to be $3.75 \mathrm{mmol} / \mathrm{g}$ by Abdul-Rehman et al. ${ }^{51}$ while Rees et al..$^{52}$ estimated $2.7 \mathrm{mmol} / \mathrm{g}$. Apparently, it is very difficult to determine the loading at high pressures. From the above we conclude that at low pressures accurate experimental data exist which can be used for a comparison with the simulation results. At high pressures the experimental data are not sufficiently accurate to be used for a quantitative comparison with the simulation results.
TABLE 2: Comparison of the Parameters for the Zeolite-Methane, -Ethane, and -Propane Interactions

\begin{tabular}{ccl}
\hline$\epsilon_{\mathrm{CH}_{n}-\mathrm{O}}(\mathrm{K})$ & $\sigma_{\mathrm{CH}_{n}-\mathrm{O}}(\AA)$ & \multicolumn{1}{c}{ ref } \\
\hline \multirow{3}{*}{133.3} & Methane & \\
169.3 & 3.214 & 15,28 \\
148.4 & 3.187 & 41 \\
97.5 & 3.14 & 20 \\
90.79 & 3.885 & 25,26 \\
& 3.694 & this work \\
72.27 & Ethane & this work \\
& 3.79 & \\
73.4 & Propane & this work
\end{tabular}

TABLE 3: Comparison of the Monte Carlo Results for Methane in Silicalite for Various Models at $T=298 \mathrm{~K}^{a}$

\begin{tabular}{lccc}
\hline \multicolumn{1}{c}{ simulation } & $\begin{array}{c}-q_{\mathrm{st}} \\
(\mathrm{kJ} / \mathrm{mol})\end{array}$ & $\begin{array}{c}\left\langle K_{\mathrm{H}}\right\rangle \\
{[\mathrm{mg} /(\mathrm{g} \text { atm })]}\end{array}$ & $\begin{array}{c}\left\langle K_{\mathrm{H}}\right\rangle_{\text {iso }} \\
{[\mathrm{mg} /(\mathrm{g} \mathrm{atm})]}\end{array}$ \\
\hline Goodbody et al. & 18 & 12.36 & \\
Goodbody (this work) & $18.3_{2}$ & $12.3_{1}$ & 11.9 \\
Bezus (this work) & $22.3_{1}$ & $53.9_{1}$ & 54.4 \\
Hufton (this work) & $18.5_{2}$ & $13.9_{1}$ & 14.1 \\
Demontis (this work) & $24.1_{1}$ & $30.8_{1}$ & 29.9 \\
present model & $20.0_{1}$ & $10.6_{1}$ &
\end{tabular}

${ }^{a} q_{\mathrm{st}}$ is the isosteric heat of adsorption, and $\left\langle K_{\mathrm{H}}\right\rangle$, the Henry coefficient. The subscript "iso" denotes that these results have been obtained from the adsorption isotherms. For comparison, the experimental heat of adsorption is $-20 \mathrm{~kJ} / \mathrm{mol}$ and the experimental Henry coefficient is $10.5 \mathrm{mg} /(\mathrm{g} \mathrm{atm})$.

B. Computer Simulations. Molecular dynamics and Monte Carlo simulations have been used to study the behavior of methane in silicalite/ZSM-5, ${ }^{6,11-15,17,20,21,24-26,28,29}$ faujasite, ${ }^{4,6,7,57}$ $\mathrm{Na}-\mathrm{A},{ }^{9,35}$ mordenite,,${ }^{6,14}$ and EU-1. ${ }^{14}$ Monte Carlo simulations of mixtures of methane and other gases in zeolites are described in refs 18,19 , and 30 . Of those who use a united atom model, the parameters are listed in Table 2. Comparison of the parameters used in the various studies shows that for the zeolite-methane interactions the values of the energy parameter $\epsilon$ may differ by almost a factor of 2 , and for the size parameter $\sigma$ differences of $25 \%$ occur. The methane-methane interactions $\left(\epsilon \mathrm{CH}_{4}-\mathrm{CH}_{4}=147.95 \mathrm{~K} ; \sigma_{\mathrm{CH}_{4}}-\mathrm{CH}_{4}=3.73 \AA\right)$ are taken from the work of Verlet and Weis ${ }^{58}$ and give a reasonable description of the vapor-liquid curve of methane. It is therefore interesting to make a detailed comparison of the various models to investigate how accurate the various sets of parameters describe the adsorption isotherms of methane in silicalite.

1. Comparison with Goodbody et al. Goodbody et al. ${ }^{15}$ reported simulations of the adsorption isotherm of methane in silicalite. The data of Goodbody et al. have been reproduced by Maginn et $a l .^{28}$ and are therefore ideal for testing our program. In Table 3 we compare the simulation results reported by Goodbody et al. ${ }^{15}$ with the results obtained from our program. These simulations are $N, V, T$ simulations of one adsorbed molecule. The agreement for the heat of adsorption and Henry coefficients is excellent. We have calculated the adsorption isotherms for a system with 4 and 8 unit cells. Our results are in excellent agreement with those of Goodbody et al. In addition we did not observe significant finite-size effects.

2. Methane-Zeolite Interactions. To test the various interaction parameters for the methane-zeolite interactions, we have calculated the Henry coefficient, heats of adsorption, and part of the adsorption isotherms for the various models. The results of these calculations are presented in Table 3. Table 3 shows that for most models the isosteric heats of adsorption are in good agreement with the experimental result, although the model used by Demontis et al. ${ }^{25}$ seems to give a value which is somewhat large. 


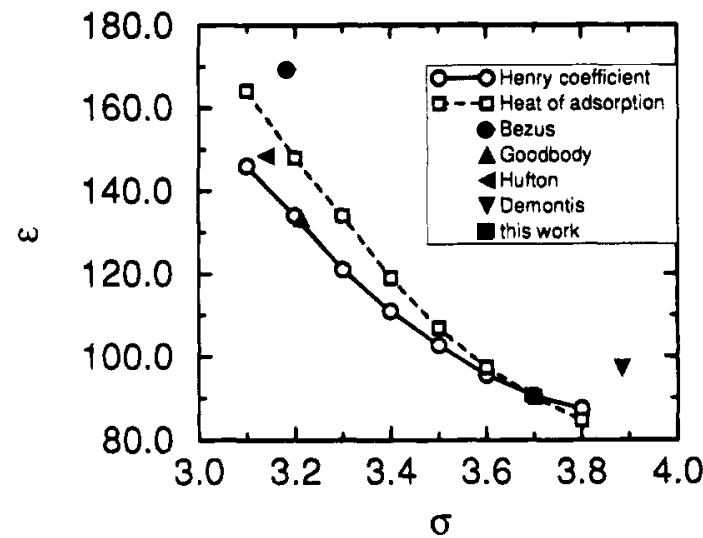

Figure 3. Optimum Lennard-Jones parameters for the heat of adsorption (dashed line with squares) and Henry coefficient (solid line with circles) of methane in silicalite. The crossing of the lines gives the parameters for which both the Henry coefficient and heat of adsorption agree with the experimental results. For comparison, the filled symbols are the parameters of the various models.

The results for the Henry coefficients show a larger variation. The model used by Bezus et al. predicts a Henry coefficient which is five times larger than the one predicted by the model of Goodbody et al. ${ }^{15}$ A test of the consistency of the results is to calculate the Henry coefficient from the adsorption isotherms at low pressures and to compare these values with a direct calculation of the Henry coefficient using the test particle insertion method. The fitted Henry coefficients are given in Table 3. These Henry coefficients are in good agreement with the ones which have been calculated directly. The models of Demontis $e t$ al. and Bezus $e t$ al. predict a significantly higher adsorption than that observed experimentally. From the available models, the model of Goodbody et al..$^{15}$ agrees best with the experimental results. In addition we have found that although the models proposed by Bezus et $a l^{41}$ and Demontis et al. ${ }^{25}$ give a good prediction of the heat of adsorption, the adsorption isotherm differs significantly from the experimental data. Apparently a good prediction of the heat of adsorption does not guarantee an accurate description of the adsorption isotherm as well; for the development of a model it is important to compare the Henry coefficients with experimental data as well.

Detailed comparison of the prediction of the model of Goodbody et al. with the experimental Henry coefficient and heat of adsorption shows that the heat of adsorption is slightly underestimated while the Henry coefficient is slightly overestimated. Note that these (small) differences occur because we use a different set of experimental data than was used by Goodbody et al. ${ }^{15}$ To see whether the model can be improved, we have calculated the values of the parameters of the LennardJones potential for the methane-zeolite interaction that reproduce the experimental Henry coefficient and heat of adsorption. The results of these simulations are shown in Figure 3. From the crossing of the two lines we can obtain the values for the Lennard-Jones parameters for which both the Henry coefficient and heat of adsorption are in agreement with the experimental data. The fact that there is such a point and that there is only one such point is an important result, since this suggests that there is a unique set of parameters which describes the properties of methane optimally. These values of the parameters are $\epsilon=$ $90.79 \mathrm{~K}$ and $\sigma=3.694 \AA$. With these values the calculated Henry coefficient is $10.6 \mathrm{mg} /(\mathrm{g} \mathrm{atm})$ and the calculated heat of adsorption $-20.0 \mathrm{~kJ} / \mathrm{mol}$. In Figure 3 we have also plotted the parameters used by the other groups. Comparison of our model with the model of Goodbody et al. shows that we have a significantly larger value for $\sigma$; our value is close to the value

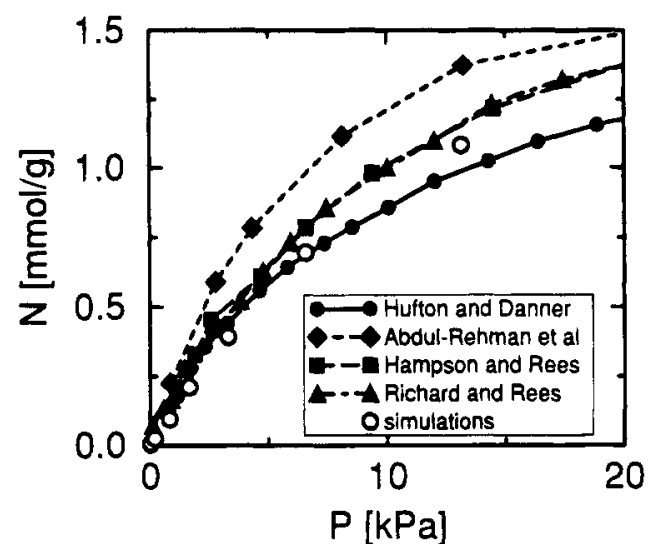

Figure 4. Comparison of the available experimental adsorption isotherms of ethane in silicalite at low pressures (filled symbols). The open symbols are the results from simulations at $T=298 \mathrm{~K}$.

used by Demontis et al. On the basis of the comparison of the model of Goodbody et al. with the experimental data, one would expect only a marginal modification of this model. The results of Figure 3 show, however, that our model deviates more than expected from the model of Goodbody et al. Note that "optimum" is defined as agreement with a particular set of experimental data. However, the specific experimental data used here are not unique; we made a "compilation" of these data and decided which values to use for our comparison. Our conclusions are therefore entirely dependent on the choices made here. We hope that more experiments will be performed to arrive at a unique experimental data set to eliminate this source of ambiguity.

3. Adsorption Isotherms. Figure 2 shows the adsorption isotherms at high pressures, where the size of the molecules dominates the energetics. Since the values of the size parameter for the zeolite-methane interactions are comparable (see Table 2 ), the results predicted by the model of Bezus et al. and Goodbody et al. converge to the same maximum loading. At pressures larger than $1000 \mathrm{kPa}$, the simulation results-as predicted by the model of Goodbody et al.- start to deviate from the experimental data of Rees et al. ${ }^{52}$ and Ding et al. ${ }^{49}$ Surprisingly, the simulation results are in good agreement with the data of Abdul-Rehman et al..$^{51}$ Since the experimental results at high pressures are not very reliable (see section IV.A), we can not draw too many conclusions from these results. In addition, in the simulations we assume silicalite to be a perfect crystal which is completely accessible to methane. Such ideal crystals are extremely difficult to make experimentally; one would therefore expect that experimental maximum loadings are systematically lower than the theoretical ones.

\section{Ethane}

A. Experimental Data. The experimental data for the heat of adsorption of ethane in silicalite are collected in Table 1. The experimental data on pure silicalite converge to a value of $-31 \mathrm{~kJ} / \mathrm{mol}$. Adsorption isotherms of ethane in silicalite have been published in refs $51,54,59$, and 60 . The data of these experimental studies are compared in Figures 4 and 5. At low coverage the data of Hufton and Danner, ${ }^{54,61}$ Richard and Rees, ${ }^{59}$ and Hampson and Rees ${ }^{60}$ are in good agreement with each other. The data reported by Abdul-Rehman et al ${ }^{51}$ deviate slightly for similar reasons as those discussed for methane (see section IV.A). To determine the Henry coefficient, we have combined the low pressure data of Hufton and Danner, ${ }^{54,61}$ Richard and Rees, ${ }^{59}$ and Hampson and Rees. ${ }^{60}$ Fitting all these data with equal weight yielded a Henry coefficient $K_{\mathrm{H}}=330 \mathrm{mg} /(\mathrm{g} \mathrm{atm})$. 


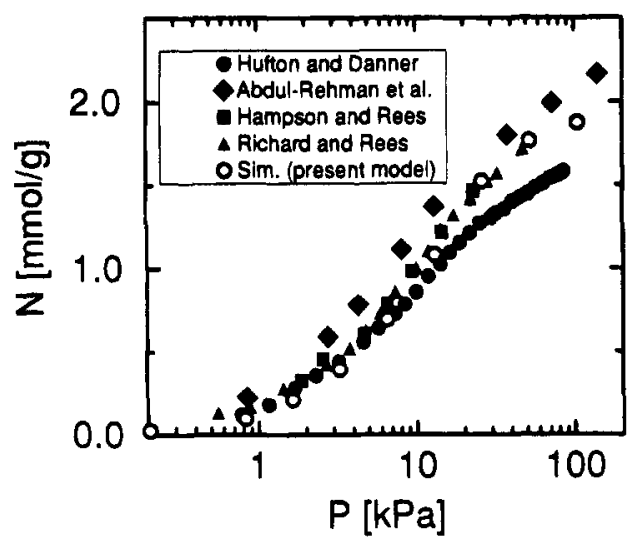

Figure 5. Comparison of experimental adsorption isotherms of ethane in silicalite with simulation data at $T=298 \mathrm{~K}$.

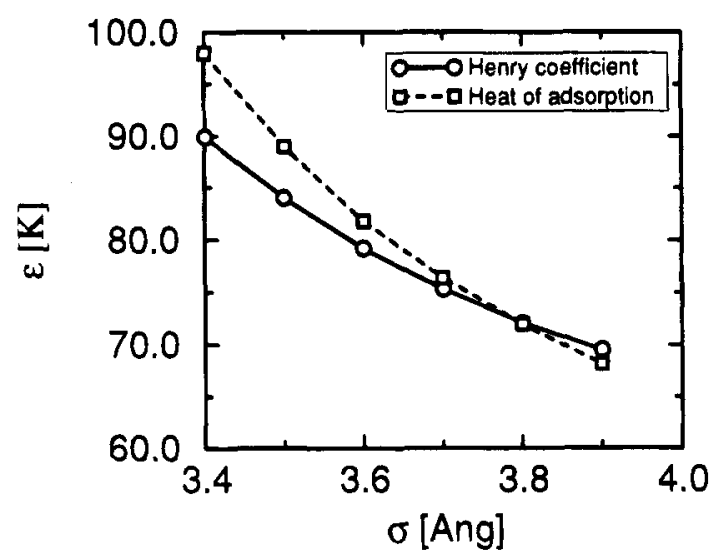

Figure 6. Optimum Lennard-Jones parameters of the heat of adsorption (squares) and Henry coefficient (circles) for ethane in silicalite. The crossing of the lines gives the parameters for which both the Henry coefficient and heat of adsorption agree with the experimental results.

This is consistent with the values $K_{\mathrm{H}}=421 \mathrm{mg} /(\mathrm{g}$ atm $)$ reported by Hampson and Rees ${ }^{60}$ and $K_{\mathrm{H}}=460 \mathrm{mg} /(\mathrm{g} \mathrm{atm})$ reported by Hufton and Danner. ${ }^{54}$ For future comparison we use as experimental data for the heat of adsorption $-31 \mathrm{~kJ} / \mathrm{mol}$ and for the Henry coefficient $330 \mathrm{mg} /(\mathrm{g}$ atm).

B. Computer Simulations. In contrast to the large number of simulations that have been published on the adsorption of methane in zeolites, there are only a few articles describing the adsorption of ethane. Titiloye et al ${ }^{16}$ used molecular mechanics to study the siting in silicalite. Catlow et al. ${ }^{17}$ and Nowak et $a l{ }^{14}$ studied the diffusion of ethane in silicalite. All these models use an all-atom representation. To our knowledge, united-atom models have not been used yet to study the adsorption of ethane in a zeolite. Before we consider the zeolite-ethane interaction, we first discuss the ethane model.

1. Ethane Model. The ethane model that is used in this work is based on the model developed by Jorgensen et al. ${ }^{62}$ The bond length is fixed at $1.536 \AA$, and the nonbonded interactions are described with a Lennard-Jones potential with parameters $\epsilon=$ $104.2 \mathrm{~K}$ and $\sigma=3.775 \AA$. The potential was truncated at 13.8 $\AA$, and the usual tail corrections have been added.

2. Zeolite-Ethane Interactions. The simulations of methane demonstrated that, in order to describe the adsorption isotherms correctly, it is important to correctly predict both the heat of adsorption and the Henry coefficient at zero loading. To determine the optimum parameters for the $\mathrm{CH}_{3}$-zeolite interactions for an ethane molecule, we used a similar procedure as that described for methane. Figure 6 shows the optimum parameters for the heat of adsorption and Henry coefficient; the intersection of the two lines $(\epsilon=72.27 \mathrm{~K}$ and $\sigma=3.79 \AA)$

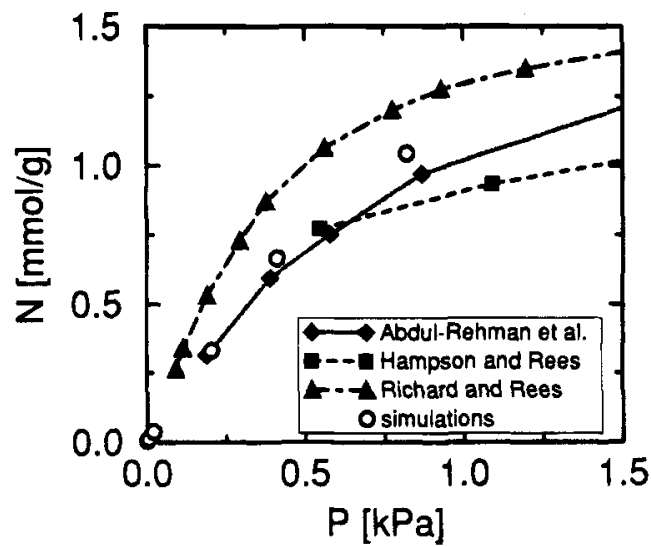

Figure 7. Comparison of the experimental adsorption isotherms of propane at low pressures.

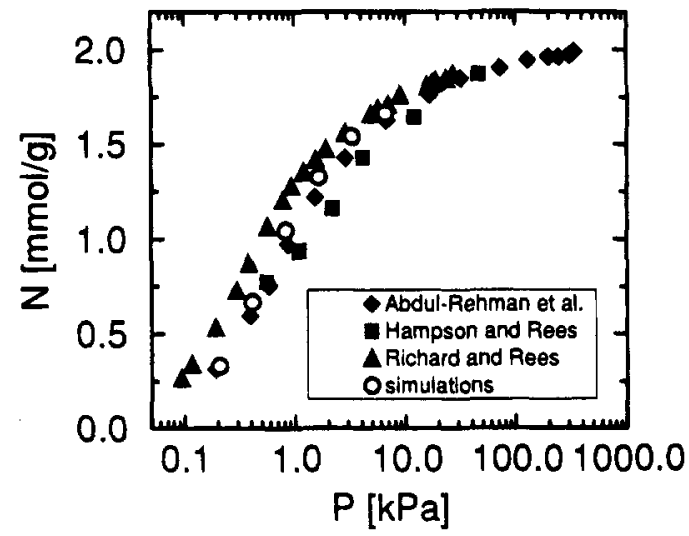

Figure 8. Comparison of experimental adsorption (filled symbols) isotherms of propane in silicalite with simulation data (open symbols) at $T=298 \mathrm{~K}$.

gives the model parameters. With this parameter set, we found a heat of adsorption of $-31.1 \pm 0.1 \mathrm{~kJ} / \mathrm{mol}$ and a Henry coefficient of $340 \pm 5 \mathrm{mg} /(\mathrm{g} \mathrm{atm})$, in good agreement with the experimental values.

3. Adsorption Isotherms. In Figure 4 the simulation results are compared with the experimental data at low pressures. The simulations are in excellent agreement with the data from Richard and Rees ${ }^{59}$ and Hampson and Rees. ${ }^{60}$ Small deviations occur with the data of Hufton and Danner ${ }^{54,61}$ and AbdulRehman et al. ${ }^{51}$

The adsorption isotherms at high pressures are shown in Figure 5. The simulation data differ significantly from the data of Hufton and Danner ${ }^{54,61}$ but are in good agreement with the data of Richard and Rees, ${ }^{59}$ Hampson and Rees, ${ }^{60}$ and AbdulRehman et al..$^{51}$ The results presented in this section show that it is possible to model the experimental adsorption isotherms of ethane in silicalite accurately. Also for ethane it would be highly desirable that more experiments would be done since the experimental data show too much scatter to draw firm conclusions on the reliability of the models.

\section{Propane}

A. Experiments. The experimental data on the heat of adsorption of propane in silicalite are collected in Table 1. The experimental data on pure silicalite converge to a value of -40 $\mathrm{kJ} / \mathrm{mol}$.

Adsorption isotherms of propane in silicalite have been published refs 51,59 , and 60 . The data of these experimental studies are compared in Figures 7 and 8 . At low coverage the data of Abdul-Rehman et al. ${ }^{51}$ and Hampson and Rees ${ }^{60}$ are in 


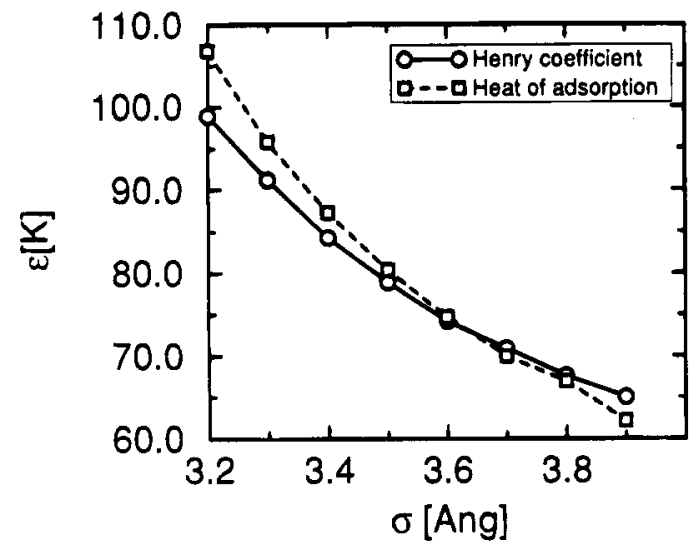

Figure 9. Optimum Lennard-Jones parameters of the heat of adsorption (squares) and Henry coefficient (circles) for propane in silicalite. The crossing of the lines gives the parameters for which both the Henry coefficient and heat of adsorption agree with the experimental results.

good agreement with each other. The data of Richard and Rees $^{59}$ deviate slightly. Note that the isotherm of Richard and Rees was measured at a temperature of $291.5 \mathrm{~K}$, while the other data are taken at $300 \mathrm{~K}$. This temperature difference can explain the difference between the data sets. From the adsorption isotherms at low pressures (Figure 7) we have determined the following Henry coefficients: $4851 \mathrm{mg} /(\mathrm{g}$ atm $)$ from the data of Abdul-Rehman et al. $.{ }^{51} 6174 \mathrm{mg} /(\mathrm{g} \mathrm{atm})$ from the data of Hampson and Rees, ${ }^{60}$ and $8379 \mathrm{mg} /(\mathrm{g} \mathrm{atm})$ from the data of Richard and Rees. ${ }^{59}$ These values are in reasonable agreement with the extrapolated result $1014 \mathrm{mg} /(\mathrm{g}$ atm $)$ obtained from chromatography by Hufton and Danner. For the determination of the propane-zeolite parameters we have used the (rounded) value of Hampson and Rees: $6200 \mathrm{mg} /(\mathrm{g} \mathrm{atm})$.

The experimental adsorption isotherms at high pressures are compared in Figure 8. All experimental data agree very well. This agreement is somewhat surprising since for methane and ethane systematic differences could be observed between the various data sets of the same sources.

B. Simulations. 1. Propane Model. We used the OPLS model of Jorgensen and co-workers ${ }^{62}$ for the description of the nonbonded interactions of propane (Lennard-Jones parameters: $\epsilon_{\mathrm{CH}_{3}}=88.06 \mathrm{~K}, \epsilon_{\mathrm{CH}_{2}}=59.38 \mathrm{~K}$, and size parameter $\sigma_{\mathrm{CH}_{3}}=\sigma_{\mathrm{CH}_{2}}=3.87 \AA$ ). Instead of a fixed bond angle, we used a bond-bending potential

$$
U_{\text {bending }}(\theta)={ }_{1}^{1}{ }_{2} k_{\theta}\left(\theta-\theta_{\text {eq }}\right)^{2}
$$

with equilibrium angle $\theta_{\mathrm{eq}}=112.4^{\circ}$ and $k_{\theta}=62500 \mathrm{~K}$.

2. Zeolite-Propane Interactions. Previous simulations of propane in silicalite of Nowak et al..$^{14}$ and Nicholas et al. ${ }^{29}$ used all-atom representations of propane.

To determine the zeolite-propane interactions, we have used a similar procedure as for methane and ethane. We have assumed that the $\mathrm{CH}_{3}$ and $\mathrm{CH}_{2}$ groups have identical interactions. The optimum parameters for the heat of adsorption and Henry coefficient are shown in Figure 9; from this plot we obtain as parameters for the Lennard-Jones potential $\epsilon=73.4 \mathrm{~K}$ and $\sigma=3.636 \AA$. With these parameters the heat of adsorption is $-39.9 \mathrm{~kJ} / \mathrm{mol}$ and the Henry coefficient $6406 \mathrm{mg} /(\mathrm{g} \mathrm{atm})$, which is in excellent agreement with experimental data.

3. Adsorption Isotherms. In Figure 7 the simulated adsorption isotherms of propane in silicalite are compared with experimental data at low pressures in Figure 7 and at high pressures in Figure 8. The agreement with experimental data is very good.

\section{Concluding Remarks}

In this paper the adsorption isotherms of methane, ethane, and propane in silicalite have been calculated using grand canonical Monte Carlo simulations. The zeolite-alkane models have been tested via a comparison of the experimental data for the Henry coefficients and heats of adsorption with the results obtained via simulations. It is shown that, among available methane-zeolite models, the model of Goodbody et al. ${ }^{15}$ performed best. A new set of methane-zeolite parameters has been introduced which yields a better prediction of the experimental data than the model of Goodbody et al. ${ }^{15}$ Also for ethane and propane new sets of parameters have been introduced which yield heats of adsorption, Henry coefficients, and adsorption isotherms that are in good agreement with experimental data.

\section{References and Notes}

(1) van Bekkum, H., Flaningen, E. M., Jansen, J. C., Eds. Introduction to Zeolite Science and Practice; Elsevier: Amsterdam, 1991.

(2) Stroud, H. J. F.; Richards, E.; Limcharoen, P.; Parsonage, N. G. J Chem. Soc., Faraday Trans. 1 1976, 72, 942-954.

(3) Soto, J. L.; Myers, A. L. Mol. Phys. 1981, 42, 971-983.

(4) Yashonath, S.; Thomas, J. M.; Nowak, A. K.; Cheetham, A. K Nature 1988, 331, 601-604.

(5) Wood, G. B.; Panagiotopoulos, A. Z.; Rowlinson, J. S. Mol. Phys. $1988,63,49-63$. 7171 .

(6) Smit, B.; den Ouden, C. J. J. J. Phys. Chem. 1988, 92, 7169-

(7) Yashonath, S.; Demontis, P.; Klein, M. L. Chem. Phys. Lett. 1988, 153, $551-555$.

(8) den Ouden, C. J. J.; Smit, B.; Wielers, A. F. H.; Jackson, R. A.; Nowak, A. K. Mol. Sim. 1989, 4, 121-136.

(9) Cohen, De Lara, E.; Kahn, R.; Goulay, A. M. J. Chem. Phys. 1989 $90,7482-7491$

(10) Pickett, S. D.; Nowak, A. K.; Thomas, J. M.; Peterson, B. K.; Swift, J. F.; Cheetham, A. K.; den Ouden, C. J. J.; Smit, B.; Post, M. J. Phys. Chem. 1990, 94, 1233-1236.

(11) June, R. L.; Bell, A. T.; Theodorou, D. N. J. Phys. Chem. 1990 , $94,1508-1516$

(12) June, R. L.; Bell, A. T.; Theodorou, D. N. J. Phys. Chem. 1990. $94,8232-8240$

(13) Snurr, R. Q.; June, R. L.; Bell, A. T.; Theodorou, D. R. Mol. Sim. 1991, 8, 73-92.

(14) Nowak, A. K.; den Ouden, C. J. J.; Pickett, S. D.; Smit, B.; Cheetham, A. K.; Post, M. F. M.; Thomas, J. M. J. Phys. Chem. 1991, 95, 848-854.

(15) Goodbody, S. J.; Watanabe, K.; MacGowan, D.; Walton, J. P. R B.; Quirke, N. J. Chem. Soc., Faraday Trans. 1991, 87, 1951-1958.

(16) Titiloye, J. O.; Parker, S. C.; Stone, F. S.; Catlow, C. R. A. J. Phys. Chem. 1991, 95, 4038-4044.

(17) Catlow, C. R. A.; Freeman, C. M.; Vessal, B.; Tomlinson, S. M.; Leslie, M. J. Chem. Soc., Faraday Trans. 1991, 87, 1947-1950.

(18) Karavias, F.; Myers, A. L. Langmuir 1991, 7, 3118-3126.

(19) Karavias, F.; Myers, A. L. Mol. Sim. 1991, 8, 51-72.

(20) Hufton, J. R. J. Phys. Chem. 1991, 95, 8836-8839.

(21) Fritzche, S.; Haberlandt, R.; Kärger, J.; Pfeifer, H.; Heinzinger, K. Chem. Phys. Lett. 1992, 198, 283-287.

(22) Vigné-Maeder, F.; Amrani, S. El.; Gélin, P. J. Catal. 1992, 134, $536-541$.

(23) Leherte, L.; Andre, J.-M.; Derouane, E. G.; Vercauteren, D. P. Int. J. Quantum Chem. 1992, 42, 1291-1326.

(24) Kawano, M.; Vessal, B.; Catlow, C. R. A. J. Chem. Soc., Chem. Commun. 1992, 12, 879-880.

(25) Demontis, P.; Suffritti, G. B.; Fois, E. S.; Quartieri, S. J. Phys. Chem. 1992, 96, 1482-1490.

(26) Demontis, P.; Suffritti, G. B.; Mura, P. Chem. Phys. Lett. 1992, $191,553-560$.

(27) June, R. L.; Bell, A. T.; Theodorou, D. N. J. Phys. Chem. 1992 $96,1051-1060$.

(28) Maginn, E. J.: Bell, A. T.; Theodorou, D. N. J. Phys. Chem. 1993 97, 4173-4181

(29) Nicholas, J. B.; Trouw, F. R.; Mertz, J. E.; Iton, L. E.; Hopfinger, A. J. J. Phys. Chem. 1993, 97, 4149-4163.

(30) Maddox, M. W.; Rowlinson, J. S. J. Chem. Soc., Faraday Trans. $1993,89,3619-3621$.

(31) Vernov, A. V.; Steel, W. A.; Abrams, L. J. Phys. Chem. 1993, 97, $7660-7664$

(32) van Tassel, P. R.; Davis, H. T.; McCormick, A. V. J. Chem, Phys. $1993,98,8919-8929$. 
(33) Snurr, R. Q.; Bell, A. T.; Theodorou, D. R. J. Phys. Chem. 1993, 97, 13742-13752.

(34) Jameson, C. J.; Jameson, A. K.; Baello, B. I.; Lim, H.-M. J. Phys. Chem. 1994, 100, 5965-5976.

(35) van Tassel, P. R.; Davis, H. T.; McCormick. A. V. Langmuir 1994, 10, $1257-1267$

(36) Smit, B.; Siepmann, J. I. Science 1994, 264, 1118-1120.

(37) Smit, B.; Siepmann, J. I. J. Phys. Chem. 1994, 98, 8442-8452.

(38) Maginn, E. J.; Bell, A. T.; Theodorou, D. N. J. Phys. Chem. 1995, $99,2057$.

(39) Catlow, C. R. A., Ed. Modelling of Structure and Reactivity in Zeolites; Academic Press: London, 1992.

(40) Smit, B. Mol. Phys., in press.

(41) Bezus, A. G.; Kiselev, A. V.; Lopatkin, A. A.; Du, P. Q. J. Chem. Soc., Faraday Trans. 2 1978, 74, 367-379.

(42) Olsen, D. H.; Kokotailo, G. T.; Lawton, S. L.; Meier, W. M. J. Phys. Chem. 1981, 85, 2238-2243.

(43) van Koningsveld, H.; Tuinstra, F.; Jansen, J. C.; van Bekkum, H. Acta Crystallogr. 1989, B45, 423-431.

(44) Allen, M. P.; Tildesley, D. J. Computer Simulation of Liquids; Clarendon: Oxford, U. K., 1987.

(45) Wood, G. B.; Rowlinson, J. S. J. Chem. Soc., Faraday Trans. 2 1989, $85,765-781$.

(46) Smit, B.; Karaborni, S.; Siepmann, J. I. J. Chem. Phys. 1995, 102, $2126-2140$.

(47) Frenkel, D.; Mooij, G. C. A. M.; Smit, B. J. Phys.: Condens. Matter 1992, 4, 3053-3076.

(48) Papp, H.; Hinsen, W.; Do, N. T.; Baerns, M. Therm. Acta 1984, $82,137-148$

(49) Ding, T.; Ozawa, S.; Ogino, Y. Zhejiang Daxue Xuebao 1988, 22, 124

(50) Yamazaki, T.; Watanuki, I.; Ozawa, S.; Ogino, Y. Langmuir 1988, 4, 433-438.

(51) Abdul-Rehman, H. B.; Hasanain, M. A.; Loughlin, K. F. Ind. Eng. Chem. Res. 1990, 29, 1525-1535.

(52) Rees, L. V. C.; Brückner, P.; Hampson, J. Gas Sep. Purif. 1991, 5 , $67-75$.

(53) Otto, K.; Montreuil, C. N.; Todor, O.; McCabe, R. W.; Gandhi, H. S. Ind. Eng. Chem. Res. 1991, 30, 2333-2340.
(54) Hufton, J. R.; Danner, R. P. AlChE J. 1993, 39, 954-961. 188.

(56) After the completion of this work, refs 53 and 55 were brought to my attention. These experimental data have not been included in the evaluation of the Henry coefficient. I would like to thank a reviewer for bringing these references to my attention.

(57) Smit, B.; den Ouden, C. J. J. Ned. Tijdschr. Natuurk. 1989, A55, $82-85$.

(58) Verlet, L.; Weis, J. J. Mol. Phys. 1972, 24, 1013-1024.

(59) Richard, R. E.; Rees, L. V. C. Langmuir 1987, 3, 335-340.

(60) Hampson, J. A.; Rees, L. V. C. J. Chem. Soc., Faraday Trans. 1993, $89,3169-3176$

(61) Hufton, J. R.; Danner, R. P. Chem. Eng. Sci. 1991, 46, 20792091.

(62) Jorgensen, W. L.; Madura, J. D.; Swenson, C. J. J. Am. Chem. Soc. $1984,106,6638-6646$. 28.

(63) Hyun, S. H.; Danner, R. P. AIChE Symp. Ser. 1982, 78 (219), 19-

(64) Yamazaki, T.; Watanuki, I.; Ozawa, S.; Ogino, Y. Nippon Kagaku Kaishi 1987, 8, 1535-1540.

(65) Chiang, A. S.; Dixon, A. G.; Ma, Y. H. Chem. Eng. Sci. 1984, 39, $1461-1468$

(66) Doelle, H.-J.; Heering, J.; Riekert, L.; Marosi, L. J. Catal. 1981, $71,27-40$.

(67) Stach, H.; Thamm, H.; Jänchen, J.; Fiedler, K.; Schirmer, W. In New Developments in Zeolite Science and Technology; Proceedings of the 6th International Zeolite Conference; Olsen, D., Bisio, A., Eds.; Butterworth: Guildford, U.K., 1984, pp 225-231.

(68) Thamm, H. Zeolites 1987, 7, 341-346.

(69) Bülow, M.; Schodder, H.; Rees, L. V. C.; Richards, R. E. In New Developments in Zeolite Science and Technology; Proceedings of the 7th International Zeolite Conference; Murakami, Y., Iijima, A., Ward, J. W., Eds.; Elsevier: Amsterdam, 1986; pp 579-586.

(70) Kiselev, A. V.; Lopatkin, A. A.; Shulga, A. A. Zeolites 1985, 5, $261-267$.

JP9430744 